\title{
Research of doctors' innovative KPIs of clinical diagnostic center in goal-setting sustainable development
}

\author{
Dmitry Kashparov*, Natalya Kubina, Lyudmila Puryzhova, Irina Kravchenko, and \\ Anastasia Kashparova \\ I. Kant Baltic Federal University, Russia
}

\begin{abstract}
Modern challenges have increased attention to the effective operation of medical institutions of various types. At first glance, the tools for achieving the goals of medical organizations have been studied and tested. However, the scientific description and research of the doctors' KPIs of a polyclinic medical organization within in goal-setting sustainable development in the context of a changing situation with a pandemic has not been sufficiently clarified. The paper presents the current forms and systems of remuneration, KPIs for employees of polyclinic medical organization, as well as a study of the motivational components of the doctors at the Clinical Diagnostic Center (CDC) of Immanuel Kant Baltic Federal University (IKBFU), functional expectations (requirements) from the CDC management with subsequent development of innovative KPIs for doctors as a key category of employees of the research object.The results of the study make it possible to develop a methodology for calculating the integral indicator of KPIs with options for the concept of remuneration for doctors in CDC. The research includes a content analysis of the sources characterizing the current scientific and practical state of the formation and application of doctors' KPIs. The basis of the study implies a comparison of the formulated tasks of CDC with the tasks of the doctors and their motivational components, followed by the formulation of indicators of doctors' performance in the context of current forms and systems of remuneration of doctors in Russia and abroad. The continuation of the research in a practical aspect will be associated with developing and implementing the integral indicator of doctors' KPIs in the approbation process. Future theoretical research is related to the formation of a methodological tool for a flexible system of remuneration for doctors based on changing challenges in goal-setting sustainable development
\end{abstract}

\section{Introduction}

Nowadays, medical organizations are undergoing serious trials and changes. External challenges lead to a change in internal processes, forcing to change and correspond to changes in order to achieve harmonious and sustainable development. In this process, the

\footnotetext{
*Corresponding author: dmitr2001@mail.ru
} 
existing tools and models that contribute to the achievement of the goals of medical organizations are not always programmed for results and require either adjustments or significant changes, within which, it is necessary to create and apply innovative mechanisms for achieving effective results that meet the requirements of the time and the goals of the organization. The movement towards one of the UN sustainable development goals approved in 2015 - "Good Health and Well-being", generates a number of tasks, one of which, in our opinion, is the compliance of one of the key driving forces in achieving this goal - a doctor, with the organizationally meaningful requirements of a medical institution. One of the elements of a doctor's organizationally meaningful activities are the indicators of their effectiveness, the professional application of which makes it more likely that the goals of a medical organization will be achieved and the subsequent movement, through the competitive implementation of its functions towards good health and wellbeing of citizens will be made. Possible innovative key performance indicators of doctors' activities in medical organizations of various profiles is a subject of research both in domestic and foreign practice, which arouses interest in a specific case - an organization, a region, etc. Well-established approaches and conservatism in defining and implementing the tools motivating proper performance and movement towards sustainable development in goal-setting medical organizations is one of the reasons for either slow development or the basis of the inability to do their job better than others do, with corresponding consequences. The indicated aspects determine the relevance of issues related to the application of innovative key performance indicators of doctors in a medical organization of special status - the University Clinic (Clinical Diagnostic Centre - CDC).

\section{Materials and methods of study}

The purpose of the study is to develop innovative KPIs for doctors as a key category of the CDC employees. The methodology for achieving this goal included:

- clarification of the purpose of the research subject (CDC),

- formulation, clarification and coordination of the CDC tasks in accordance with the purpose of the activity for a certain period,

- research of forms and systems of remuneration, KPIs of employees of medical polyclinic organizations,

- development of a list of KPIs for the CDC doctors.

Sources of information

- Secondary information - internal reporting of CDC and IKBFU.

- Primary information - the research findings of the CDC management and staff

Methods for collecting primary information - a survey (questionnaire).

When developing KPIs for doctors, the main requirements for KPIs were taken into account:

- connection with the goals of the organization,

- achievability (the degree of achievement should be above $80 \%$ ),

- adaptability to changes in the organization environment (internal and external),

- specificity (clear quantitative, qualitative and time characteristics of the goal),

- general accessibility (for understanding employees of all levels),

- harmony (interconnection),

- causing other positive changes in the organization,

- motivational focus for staff,

- relevance (periodic review, taking into account the purpose and objectives),

- validity 


\section{Results and discussion}

\subsection{Forms and systems of remuneration, KPI of employees in medical institutions of polyclinic type}

The staffing table of policlinic medical organizations includes a list of employees who ensure the functioning of the organization as a whole. The research focuses on the category of employees - doctors.

Medical organizations effectively apply a mixed form of the existing forms, that combines the elements of the result and the time used. This form gives rise to a system of remuneration for doctors, in which there is a basic (fixed part) and incentive (variable part). The ratio of these parts is individual for medical, organizations depending on many factors. The research has shown that there are many approaches and views on the forms and systems of remuneration for doctors. Sagdeev P.P. and Afonin Yu.A. propose a ratio in salaries of 70/30 - fixed and variable parts, where the variable is designed to stimulate employees and includes additional payments for work experience, professionalism, mentoring, and work results [9].

Russian modern practice shows that the salary of medical workers consists of several components: basic salary, increments (for category, service length, work complexity, workload), compensation (for harm, inflation).

Based on the research of the resource for placing vacancies in medical organizations, as well as the data from the Ministry of Health on the example of the Kaliningrad region, the salary of doctors is a within the range of 30-70 thousand rubles. $[14,15]$. At the same time, it is necessary to take into account the real deviation from the declared figures, as a rule, to a larger figures when meeting the indicators established in a particular organization for a particular employee (from 10 to $30 \%$ ), as well as possible participation in grants and scientific and practical projects. A deviation downward is also possible (as a rule, at the beginning of work within 10-25\%) The amount of remuneration is also influenced by the "scarcity" of labor resources. With a shortage of specialists in leading medical organizations, employers offer social assistance and provide housing for novice specialists and doctors from other cities and countries.

The results are expected from the activities of medical organizations no less than from other organizations in the socio-economic development of the country. As part of stimulating performance results, key performance indicators (KPIs) are applied. the indicators of the organization's functioning, which are set to achieve certain strategic goals, among other things, as a tool for recording labor results and staff motivation". "World practice proves that the introduction of a KPIs system in a wide variety of industries (including medicine) can increase the company's performance by $10-30 \%$, primarily due to the fact that it orients the work of employees towards a specific result" [9].

The research conducted by the authors revealed the existence of a fairly wide list of possible KPIs for doctors (excluding pandemic restrictions) [1,2,3,5,8]. Let us highlight the most common of them:

- Reducing the hospitalization rate of the assigned population,

- Coverage of preventive vaccinations,

- Reducing the frequency of ambulance calls,

- Comprehensiveness of medical and prophylactic service of patients who are under dispensary supervision;

- The number of newly diagnosed patients,

- Comprehensiveness of fluorographic examination,

- Comprehensiveness of bacterioscopic examination,

- Absence of neglected cases of tuberculosis, 
-The number of newly diagnosed patients with arterial hypertension,

- Absence of cases of oncological diseases with visible localizations, identified on 3-4 clinical stages,

- Justification of prescribing medicines,

- The proportion of children under dispensary supervision of the total number,

- Primary / general morbidity in children;

- The mortality rate of the assigned population, in comparison with the same period last year (introduced as the main indicator of health in accordance with the Decree of the President of the Russian Federation);

- Availability of substantiated complaints;

- Emergency work performance of increased volume / work of increased complexity,

- Application of unique diagnostic and / or treatment technologies;

- Mentoring / mastery / transfer of experience.

It is important to emphasize that the above mentioned and other indicators are not universal and do not provide a guaranteed result when applied without taking into account the goals of the organization, its tasks and functioning features.

The development of a technology for assessing doctors' work and motivational mechanisms based on indicators of a doctor's effectiveness and efficiency is a task and often a problem for the head of a polyclinic medical organization [4]. The motivation mechanism for doctors should be based on the goals of an organization and, as much as possible, should reflect the professionalism and ability of a doctor to perform the assigned tasks. The introduction of a stimulating remuneration system is one of the conditions for enhancing the activity of a doctor in the framework of ensuring the quality of medical care [4-5].

In the system of organizing the service provision, i.e., a medical service, in the process of commercializing the service provision (a medical service), an important component is the system of interaction between a service provider (a doctor) and a service consumer (a patient). The competencies of working with patients who are clients of a clinical organization, extending to the question "How to minimize the client's costs?" are the tasks of a competitive doctor in modern conditions. [5]

The research allows to formulate possible indicators when assessing interaction with patients (clients of a medical organization):

- dynamics of the total flow / target group of patients;

- increase in the number of clients,

- patients' satisfaction,

- proportion of clients by recommendation,

- waiting time for a doctor's appointment (minutes);

- the average waiting time of the results of a prescribed diagnostic test, (days),

- satisfaction with the medical service provided,

- patients' satisfaction with the courtesy and attention of the medical staff.

In the Moscow region, the following groups of criteria have been formed to assess the chief doctors of polyclinics: 1) "finance", 2) "patient", 3) "organization of work", 4) "personnel". Each group contains from 4 to 7 criteria [6].

Peskova O.S., Boriskina T.B., Markacheva A.S., in their research note that "... in order to increase profits in medical institutions, KPIs are applied aiming specifically at improving the medical service quality, expanding services and staff efficiency" ... "A healthcare professional should be directly interested in the quality performance of daily tasks, because they will receive remuneration for them, and their individual plan should reflect the overall plan of the entire organization. With KPIs, medical institutions can measure the activity as a whole and its sub-processes:

1. The beneficial effect for which a medical organization works. 
2. A side effect that is an undesirable outcome of an activity.

3. Expenditure of resources and time.

4. The ratio of useful effect and time (resources) consumption.

When developing KPIs, a medical organization needs to focus not on one, but on four indicators that characterize its activities: finance, patients, internal business processes and personnel [7].

As one of the options for KPIs indicators for doctors in the Kaliningrad region, let us consider an example for a therapist [16]:

- Proportion of visits with preventive purposes in the total number of visits;

- The level of hospitalization of the population at the health locality;

- Reasonable complaints;

- Satisfaction with the quality of medical service provided;

- Absence of advanced cases of oncological diseases (in terms of manageable causes);

- Coverage of the adult population assigned to dispensary supervision

When developing a KPIs mechanism for doctors in a number of foreign countries (the USA, Great Britain, New Zealand), "the planned values of performance indicators are modeled using the so-called system-dynamic approach (it takes into account the dynamics of the characteristics in medical organizations)" [10,11].

It is noted that a unified system does not yet exist and perhaps, a unified system is not advisable, since it is necessary that the individual characteristics of an organization should be taken into account. "The introduction of the KPIs system in each specific case requires a creative approach and high qualifications of managers who have a holistic understanding of the effective mechanisms for achieving the goals of the organization" $[12,13]$. The values of the remuneration level of a doctor abroad are related to the forms and systems of payment, taking into account individual goals, objectives and other factors for a medical organization.

\subsection{Research of motivational components of CDC doctors, functional expectations of management and development of innovative KPIs for doctors}

The conducted research required taking into account the purpose of the organization for a certain period - "To take a leading position in the health care system in terms of the quality and innovative approach of the medical services provided." Within the framework of the goal, in the course of the study, a list of tasks was approved:

1. Implementation of the continuing education system within the framework of thematic improvement of doctors.

2. Formation of a positive image.

3. Entering the system of compulsory health insurance with the creation of a student clinic.

4. Creation of the Scientific and Practical Center as part of CDC and a student clinic.

5. Organization of scientific societies for students.

6. Interaction with the flagships of scientific and practical activities at the federal level, including telemedicine consultations and joint educational programs.

7.Inroduction of a modern quality control system and standardization of medical activities.

8. Creation of an international center for telemedicine consultations.

The management of CDC outlines the tasks of a specialist doctor (Table 2).

In order to develop an effective KPIs system for doctors as a tool to motivate achieving the organization's goal, a comparison was made of the formulated tasks of the organization and the tasks and categories of employees - doctors, (the management of CDC is in the role of the experts). Each of the tasks for the position of "a doctor", at least minimally (one 
match) corresponds to one task for the goals of the organization, with the exception of the employee's task - "Supervision of graduate students' and residency's training". Formally (methodically), this task for doctors is not relevant for the period of validity of the CDC tasks indicated earlier (in accordance with the goal). For the formulating doctors' KPIs for a designated period, this task was also not further taken into account.

In order to understand the motivational components of the CDC employees and the subsequent application of the data in developing KPIs, a survey was conducted in which $85 \%$ of the CDC doctors participated. In addition to introductory questions about the needs that determine the work behavior and attitude to work, the factors affecting labour motivation, possible problems in implementing doctors' practical activities, the questions were asked that were the key in developing the criteria and KPIs indicators of employees, allowing, on the one hand, to find out the understanding of the organization's goals, on the other hand, to understand the possible parameters of the activities that require their inclusion in the composition of tools that stimulate a certain activity. Describing the processes in which employees participate, the respondents did not show a complete understanding of their role and their place in their work as a doctor and the activities of the organization - CDC. Comparing the answers received with the tasks of CDC, it was revealed that a number of tasks that are set by the organization for doctors are not covered by the real activities of the studied category of employees. The vision of doctors regarding possible indicators and parameters for measuring their activities in the organization showed the "polarity" of opinions and, at the same time, made it possible to identify quite specific areas of doctors' activities that can be applied in developing KPIs as a tool to achieve the goal of CDC (Table 1). The indicators in Table 1 are formulated by the authors of the study. The areas and indicators were analyzed in the context of the organization's goals (CDC)..

A number of questions in the study of motivational components made it possible to identify intra-organizational processes that were not previously considered as motivational components in achieving results of the CDC activities and were recommended both in terms of developing a KPI methodology and for a program of intra-organizational changes.

Table 1. Table 1. Indicators and areas of doctors' activity in CDC.

\begin{tabular}{|c|c|}
\hline Areas of doctors' activity & Indicators \\
\hline Defect rate in medical care & The number of defects \\
\hline Continuity with other medical organizations & Frequency of contacts in solving problems \\
\hline Work intensity, relevance by patients & Over-fulfillment of the appointments \\
\hline \multirow{4}{*}{ The quality of medical care, its effectiveness } & $\begin{array}{l}\text { Follow-up visits in case of an unresolved problem with } \\
\text { a disease }(\%)\end{array}$ \\
\hline & $\begin{array}{l}\text { Percentage of surgical operations with late treatment or } \\
\text { a patient's lack of desire to be treated }\end{array}$ \\
\hline & Recovery in statistical time periods \\
\hline & Improvement in chronic cases \\
\hline The degree of usefulness of the doctor for CDC & Increase in an employee's performance a year \\
\hline Performance of surgical treatment in CDC & $\begin{array}{l}\text { Medical services are provided in a timely manner for a } \\
\text { patient when he or she applies to CDC }\end{array}$ \\
\hline \multirow[b]{2}{*}{ Participation in the educational process } & Giving lectures on a specialized academic subject \\
\hline & $\begin{array}{l}\text { Creation and management of the form of transfer of } \\
\text { expertise }\end{array}$ \\
\hline \multirow{3}{*}{ Patients' credibility level } & Positive feedback \\
\hline & Patients according to recommendations \\
\hline & The absence of patients' complaints \\
\hline \multirow{2}{*}{ Efficiency of the organization's work } & $\begin{array}{l}\text { No violations in compliance with the standards of the } \\
\text { medical service provision }\end{array}$ \\
\hline & $\begin{array}{l}\text { The number of a patient's visits to achieve results in } \\
\text { treatment }\end{array}$ \\
\hline Labor results on certain work volumes & No time deviations in work performance \\
\hline
\end{tabular}


Based on comparing the tasks of doctors with the tasks of CDC (based on the goal), the researchers formulated the indicators of the doctors' performance (Table 2)

Table 2. Goals of CDC specialists and performance indicators.

\begin{tabular}{|c|c|}
\hline Goals of doctors-specialists & Indicators \\
\hline \multirow{2}{*}{$\begin{array}{l}\text { Choosing the area of scientific } \\
\text { activity in clinical medicine }\end{array}$} & $\begin{array}{l}\text { Writing papers in the scientific research (selected in CDC) in } \\
\text { clinical medicine }\end{array}$ \\
\hline & $\begin{array}{l}\text { Participation in scientific research (selected in CDC) in clinical } \\
\text { medicine }\end{array}$ \\
\hline \multirow{3}{*}{$\begin{array}{l}\text { Be a unique specialist in the chosen } \\
\text { area }\end{array}$} & Having a unique advantage in the effective activity \\
\hline & Demand for a unique advantage in work \\
\hline & $\begin{array}{l}\text { Increase in the CDC indicators due to the demand for a unique } \\
\text { advantage in work }\end{array}$ \\
\hline \multirow{5}{*}{$\begin{array}{l}\text { Compulsory scientific activity and } \\
\text { writing a thesis research }\end{array}$} & Writing papers in the area of scientific activity. \\
\hline & Participation in scientific research \\
\hline & Presentations at all-Russian and scientific conferences \\
\hline & Documentary recognition of the scientific activity results \\
\hline & $\begin{array}{l}\text { Application of documented recognized result of scientific } \\
\text { activity in the practice of CDC }\end{array}$ \\
\hline $\begin{array}{l}\text { Work in schools for patients and } \\
\text { their relatives according to their } \\
\text { profile }\end{array}$ & Supervision a school for patients and event management. \\
\hline \multirow{2}{*}{$\begin{array}{l}\text { Assistance in training graduate } \\
\text { students and residents }\end{array}$} & Supervising the activities of a graduate student and (or) resident \\
\hline & $\begin{array}{l}\text { Publication of scientific papers in collaboration with a graduate } \\
\text { student and (or) a resident }\end{array}$ \\
\hline $\begin{array}{l}\text { Conducting training courses for } \\
\text { doctors in the region }\end{array}$ & Course delivery \\
\hline $\begin{array}{l}\text { Assistance or participation in } \\
\text { courses in the online space }\end{array}$ & Online course delivery \\
\hline \multirow{3}{*}{$\begin{array}{l}\text { Preparation of telemedicine } \\
\text { consultations in the region }\end{array}$} & Conducting telemedicine consultations in the region \\
\hline & Conducting telemedicine consultations at the federal level \\
\hline & Conducting telemedicine consultations at the international level \\
\hline \multirow{2}{*}{$\begin{array}{l}\text { Patients' admission and preparing } \\
\text { them for the concilium or } \\
\text { telemedicine consultations }\end{array}$} & Preparing a patient for the conciliumn \\
\hline & Preparing a patient for a telemedicine consultation \\
\hline \multirow{3}{*}{$\begin{array}{l}\text { Mastering innovative methods of } \\
\text { diagnosis and treatment in the } \\
\text { workplace }\end{array}$} & $\begin{array}{l}\text { Application of an innovative method in diagnostics and (or) } \\
\text { treatment }\end{array}$ \\
\hline & $\begin{array}{l}\text { Relevance of the applied innovative method in diagnosis and } \\
\text { (or) treatment }\end{array}$ \\
\hline & $\begin{array}{l}\text { Increase in the CDC indicators due to the application of an } \\
\text { innovative method in diagnosis and (or) treatment }\end{array}$ \\
\hline
\end{tabular}

With regard to the conditionally divided functions of doctors into production and marketing by the CDC management, the expected results, taking into account the purpose of the organization, the direction of participation and a doctor's influence on the organization processes, the indicators of measuring these results, as well as their possible target value. were formulated

According to the doctors' opinions and the management of CDC, with additions made by the authors of the study, based on the tasks of CDC in accordance with the objective of the organization (Table 3), the areas of employees' activity (doctors') were ranked based on the assessment criteria. The main criteria for assessing the KPIs indicators for doctors by the CDC management were: target orientation (importance), achievability (realistic implementation), measurability (specificity), comprehensibility and motivational focus for doctors. On the basis of expert assessments of the CDC management and in accordance with the criteria for assessing KPIs for doctors, the most important KPI indicators were identified. 
Table 3. Performance indicators of doctors in accordance with CDC objectives.

\begin{tabular}{|c|c|c|c|c|c|c|c|c|}
\hline \multirow[t]{2}{*}{ Indicators } & \multicolumn{8}{|c|}{ CDC goals] } \\
\hline & 1 & 2 & 3 & 4 & 5 & 6 & 7 & 8 \\
\hline $\begin{array}{l}\text { Patients' admission according to the policies of CHI (Compulsory Health } \\
\text { Insurance) }\end{array}$ & & & $\mathrm{X}$ & & & & & \\
\hline $\begin{array}{l}\text { Patients' admission according to the policies of } \mathrm{CHI} \text { in the policlinic for } \\
\text { students }\end{array}$ & & & $\mathrm{X}$ & & & & & \\
\hline $\begin{array}{l}\text { Supervision of a resident's work in the polyclinic for students when } \\
\text { admitting patients according to policies of OHI (Obligatory Health } \\
\text { Insurance) }\end{array}$ & $\mathrm{X}$ & $\mathrm{X}$ & $\mathrm{X}$ & & & & & \\
\hline $\begin{array}{l}\text { Supervision of a resdent's work in the polyclinic for students when } \\
\text { admitting patients }\end{array}$ & $\mathrm{X}$ & $\mathrm{X}$ & $\mathrm{X}$ & & $\mathrm{X}$ & & & \\
\hline Absence of violations in work (in accordance with the job description) & & $\mathrm{X}$ & & & & & $\mathrm{X}$ & \\
\hline Absence of complaints from clients (patients) & & $\mathrm{X}$ & & & & & $\mathrm{X}$ & \\
\hline Absence of mistakes in work & & $\mathrm{X}$ & & & & & $\mathrm{X}$ & \\
\hline Customer (Patient) satisfaction & & $\mathrm{X}$ & & & & & $\mathrm{X}$ & \\
\hline Implementation of planned indicators & & $\mathrm{X}$ & & & & & $\mathrm{X}$ & \\
\hline Absence of overspending of consumables & & & & & & & $\mathrm{X}$ & \\
\hline Creating or maintaining a leadership indicator in the professional profile & $\mathrm{X}$ & $\mathrm{X}$ & & $\mathrm{X}$ & $\mathrm{X}$ & $\mathrm{X}$ & & $\mathrm{X}$ \\
\hline $\begin{array}{l}\text { Practicing application of unique advanced diagnostic or treatment } \\
\text { technologies }\end{array}$ & $\mathrm{X}$ & $\mathrm{X}$ & & $\mathrm{X}$ & $\mathrm{X}$ & $\mathrm{X}$ & & $\mathrm{X}$ \\
\hline Average dynamics of improvement in a patient during treatment & & $\mathrm{X}$ & & $\mathrm{X}$ & $\mathrm{X}$ & $\mathrm{X}$ & $\mathrm{X}$ & $\mathrm{X}$ \\
\hline $\begin{array}{l}\text { Doctor's workload (how much time is available in the schedule for } \\
\text { appointments and how many patients are eventually admitted by the } \\
\text { doctor) }\end{array}$ & & $\mathrm{X}$ & $\mathrm{X}$ & & & & $\mathrm{X}$ & \\
\hline Absence of complications during the treatment of the patient(s)) & & $\mathrm{X}$ & & & & $\mathrm{X}$ & & \\
\hline $\begin{array}{l}\text { Exceeding the norms of performing the function of a medical position } \\
\text { (intensity)) }\end{array}$ & & $\mathrm{X}$ & & & & & & \\
\hline Performing emergency work when necessary (tension at work) & & $\mathrm{X}$ & & $\mathrm{X}$ & & $\mathrm{X}$ & $\mathrm{X}$ & $\bar{X}$ \\
\hline $\begin{array}{l}\text { Performing the work of an increased volume when the need arises } \\
\text { (tension at work) }\end{array}$ & & $\mathrm{X}$ & & $\mathrm{X}$ & & $\mathrm{X}$ & $\mathrm{X}$ & $\mathrm{X}$ \\
\hline $\begin{array}{l}\text { Performing the work of particular complexity when the need arises } \\
\text { (tension at work) }\end{array}$ & & $\mathrm{X}$ & & $\mathrm{X}$ & & $\mathrm{X}$ & $\mathrm{X}$ & $\mathrm{X}$ \\
\hline Serving as a mentor & $\mathrm{X}$ & & & $\mathrm{X}$ & $\mathrm{X}$ & $\mathrm{X}$ & $\mathrm{X}$ & \\
\hline Participation in the events in the external environment on behalf of CDC & & $\mathrm{X}$ & & & & $\mathrm{X}$ & & $\mathrm{X}$ \\
\hline Changes in the flow of patients (clients) & & $\mathrm{X}$ & $\mathrm{X}$ & $\mathrm{X}$ & & $\mathrm{X}$ & & $\mathrm{X}$ \\
\hline Customer base growth & & $\mathrm{X}$ & $\mathrm{X}$ & $\mathrm{X}$ & & $\mathrm{X}$ & & $\mathrm{X}$ \\
\hline Patient's (client's) satisfaction & & $\mathrm{X}$ & $\mathrm{X}$ & $\mathrm{X}$ & & $\mathrm{X}$ & & $\mathrm{X}$ \\
\hline Perception of the adequacy of the doctor's service price & & $\mathrm{X}$ & & & & & & \\
\hline Proportion of patients willing to recommend $\mathrm{CDC}$ for medical services & & $\mathrm{X}$ & & & & & & \\
\hline Satisfaction of patients (clients) with politeness and attention & & $\mathrm{X}$ & & & & & & \\
\hline $\begin{array}{l}\text { Conducting a permanent thematic seminar within the framework of } \\
\text { thematic enhancement of doctors in the region }\end{array}$ & $\mathrm{X}$ & $\mathrm{X}$ & & & & & & \\
\hline Guidance of the student scientific circle & & $\mathrm{X}$ & & & $\mathrm{X}$ & & & \\
\hline Conducting telemedicine consultations & & $\mathrm{X}$ & & & & $\mathrm{X}$ & & \\
\hline $\begin{array}{l}\text { Participation in the educational programme of the federal level as a co- } \\
\text { executor }\end{array}$ & & $\mathrm{X}$ & & & & $\mathrm{X}$ & & $\mathrm{X}$ \\
\hline Participation in the program "Vesti CDC" & & $\mathrm{X}$ & & & & $\mathrm{X}$ & & \\
\hline $\begin{array}{l}\text { Improvement of the quality control system and (or) the standard for the } \\
\text { medical services provision. }\end{array}$ & & & & & & & $\mathrm{X}$ & \\
\hline
\end{tabular}

At the subsequent stages of the study, in conjunction with the CDC management, the units of the KPIs measurement were formulated, and both the significance (weight) of each indicator in achieving the goals of CDC and the planned values of the indicators were established. 


\section{Conclusions}

With accounts of domestic and foreign experience, the analysis carried out in the study made it possible to develop a list of key performance indicators (KPIs) for the employees of a polyclinic medical organization (the doctors of CDC) correlated with the objective of the organization.

The results of the study, both in terms of the methodology and in terms of the findings, can be applied by medical institutions, taking into account their multidirectional functions, the specifics of goals and other aspects of organizationally meaningful activity in a changing environment for progressive sustainable development.

\section{Reference}

1. Ministry of Health and Social Development of the Russian Federation. Order of May 11, 2007 N 325 "On approval of criteria for assessing effectiveness of general practitioner (family doctor)."

2. Ministry of Health of the Nizhny Novgorod Region. Order of February 27, 2015 N 755 "On formation of key performance indicators (KPIs) of medical organizations in the Nizhny Novgorod region (as amended on March 15, 2016)."

3. L. A. Ilyukhina, Labour economics and personnel management, 3 (2014)

4. M. K. Kasumova, Institute of Dentistry, 3(64), 6 (2014)

5. O. A. Latukha, Novosibirsk State Medical University Bulletin. Year, 1(1), 230 (2017)

6. A. Kostin, Health Manager, 7 (2011)

7. V. M. Levanov, E. A. Perevezentsev, L. Yu. Garin, Medical almanac., 5(56) (2018)

8. O. S. Peskova, T. B. Boriskina, A. S. Markacheva, Economics and Entrepreneurship, 3(1) (2017)

9. P. P. Sagdeev, Yu. A. Afonin, Bulletin of Samara State University of Economics, 12(98) (2012)

10. A. L. Temnitsky, Sociological Research, 4, 90 (2018)

11. S. Roy, Asian Journal of Pharmaceutical and Clinical Research, 7(2), 9 (2014)

12. A. M. C. McGregor, O. Orlov, R. Baevsky A. Chernikova, V. Rusanov, 19th AIAA Non-Deterministic Approaches Conference (2017)

13. I. V. Nepryadkina, Family medicine, 5(55), 129 (2014)

14. A. Trzos, K. Długosz, Safety and non-mining engineering, 39, 173 (2015)

15. Job search site, https://kaliningrad.hh.ru

16. Official website of the Ministry of Health of the Kaliningrad Region, https://www.infomed39.ru

17. Electronic fund of legal and normative-technical documentation "Consortium Codex", http://docs.cntd.ru 